articles

\title{
Small Business Development Centers and Rural Entrepreneurial Development Strategies: Are We Doing Enough for Rural America?
}

\author{
Timothy C. Dunne ${ }^{1}$, Katie Toyoshima ${ }^{2}{ }^{b}$, Michael Byrd $^{2}{ }^{c}$ \\ ${ }^{1}$ Department of Managment, Boise State University, ${ }^{2}$ Boise State University \\ Keywords: Rural Entrepreneurship, Small Business Development Center, Strategy \\ https://doi.org/10.53703/001c.29493
}

\section{Journal of Small Business Strategy}

Vol. 31, Issue 4, 2021

\begin{abstract}
Many states across the United States have significant rural populations, which typically face different sets of challenges than those closer to urban populations. This is particularly evident in the different types of opportunities that small businesses face in those rural areas. In recent years, various efforts - both at a national and local level - have been taken to increase those opportunities for rural small businesses. However, those efforts have not always produced the results that are envisioned. Utilizing information about Small Business Development Center (SBDC) strategies to serve small businesses in both rural and urban areas, we highlight the efforts that work to aid rural entrepreneurs as well as those that fall short.
\end{abstract}

\section{Introduction}

Entrepreneurship and small businesses account for a significant proportion of the U.S. economy comprising $99 \%$ of U.S. firms (Small Business Trends, 2021). The impact of these small businesses offers employment opportunities, as well as both economic and community benefits (Peake et al., 2020). Moreover, within this context, urban entrepreneurship and small business ownership is a key component of the general economy, and especially important in many parts of the United States. In fact, in some states, such as the sample for our study, rural entrepreneurship makes up about two-thirds of the businesses in the state (Cicero, 2018). And, while both national and local agencies attempt to provide resources to these under-resourced rural businesses, the positive impacts have not been as numerous as those provided to more urban entrepreneurs. In this paper, we seek to highlight some of the shortcomings of efforts aimed to help rural businesses.

America's Small Business Development Centers (SBDCs) offer many resources to help aspiring entrepreneurs and small business owners across the country. Hosted by academic institutions, and funded partially by the U.S. Congress, SBDCs offer zero-cost business consulting to small business partners to help resource strapped entrepreneurs get up and running. And, while SBDCs deploy resources specifically focused towards helping rural entrepreneurs, there are some things they do that are not having the same impact in rural settings as they are having closer to urban centers. The purpose of this paper is to examine those strategies that are used by SBDCs to help rural entrepreneurs, and highlight aspects about those strategies that are ineffective or can be

\footnotetext{
a Corresponding Author Department of Management

College of Business and Economics

Boise State University

1910 University Drive, Boise, ID 83725, USA

208.426.5022

timothydunne@boisestate.edu

b Boise State University

Micron Business \& Economics Building

2360 W. University Dr. Suite 2132

Boise, Idaho 83725, USA

208.426.1640

katietoyoshima@boisestate.edu

c Boise State University

Micron Business \& Economics Building

2360 W. University Dr. Suite 2132

Boise, Idaho 83725, USA

208.426.1640

michaelbyrd@boisestate.edu
} 
improved upon.

While the literature has struggled to agree on a single definition of entrepreneurship or to delineate between small business and entrepreneurial endeavors (Howorth et al., 2005), our interest here is more about the services that SBDCs provide to both of these groups. Thus, the definition of entities in this study falls within the U.S. Small Business Administrations mission that "The office of Entrepreneurial Development's mission is to help small businesses start, grow, and compete in global markets.”

\section{SBDC Small Business Assistance}

The SBDC provides assistance through technical advice and business consulting to small business owners though local development centers. The centers provide no charge face-to-face consulting, training programs, business plan development, marketing strategies, regulatory advice, and access to capital networks. Across all of the country's 62 SBDCs, they report helping aspiring entrepreneurs get access to $\$ 5.6$ billion in financing, with a return of $\$ 123.5$ million in federal or state revenues (Chrisman, 2019). In addition to economic impacts, the businesses that America's SBDCs help created over 99,000 new jobs during the 2017 - 2018 period, bolstering the health of many communities across the country (Chrisman, 2019).

SBDC strategies to help their clients include specialized consulting and other services that target specific needs of aspiring entrepreneurs and small business owners (America's Small Business Development Center, 2021). These services may range in complexity and scope depending on the individual needs of the business or entrepreneur seeking assistance. For example, SBDCs may help an aspiring entrepreneur, who has a good idea, but little experience in industry, develop a detailed business plan. Or, they may help a small business owner struggling with sales, help to better understand the profile of their customers, leading to more targeted and efficient marketing strategies. While many of these services may seem identical for rural and urban businesses, we have found this to be false as often as it is true. Moreover, it seems that the implementation of these strategies are more effectively adopted when SBDC consultants are more familiar with the communities, which is more common closer to urban centers. We have also observed slightly different mindsets in areas where these rural businesses are located, which can result in a lack of understanding of the nuances associated with these rural enterprises.

\section{SBDC Requirements for Rural Assistance}

Under section 5.1.3.3 of the 2020 OSBDC Funding Opportunity Announcement, SBA requires SBDCs to assist "small businesses in rural areas in an effort to increase their participation in exporting, government procurement, tourism, access to credit, incubators, innovation and technology and other small business programs, in cooperation with the U.S. Department of Commerce (DOC) and other relevant Federal Agencies" (U.S. Small Business Administration Office of Small Business Development Centers, 2019). Additionally, in the Rural Development Guidelines section, 8.2.14, it states that "SBDC Applicants must make a full range of business development and technical assistance services available to small businesses located in rural areas. These services will be designed to increase rural small business participation in exporting, government procurement, tourism, access to credit, incubators, innovation and technology and other small business programs." (U.S. Small Business Administration Office of Small Business Development Centers, 2019).

In the 2020 OSBDC Funding Opportunity Announcement, providing "counseling and training to rural entrepreneurs and small business owners" is included on a list of the most important priorities for grant recipients in 2020 (U.S. Small Business Administration Office of Small Business Development Centers, 2019).

In summary, SBDCs are required to make the same assistance available to rural communities as is already available to urban communities but by no means held to any tangible metrics or targets to develop training and consulting methods to specifically serve rural entrepreneurs or small businesses. It seems that SBA would like SBDC's to market to and target rural entrepreneurs and small businesses but they implement no standards or goals to ensure that this "priority" is actually met. With this lack of metrics as the backdrop, we seek to explore areas of SBDC service that can potentially help rural entrepreneurs more effectively.

\section{The Context of our Study}

Most of our analysis will focus on the state of Idaho due to its large proportion of rural areas. However, the strategies discussed can be applied on a larger scale and many of the socioeconomic issues plaguing our rural communities are similar to those in other predominantly rural states.

Rural Idaho makes up greater than $90 \%$ of the state's geographical area and comprises 37 of Idaho's 44 counties (Morrow, 2017). All but six of Idaho's counties are under the population threshold of 65,000 needed for the American Community Survey to release annual estimates and are only included in the 5-year estimates. In fact the average population of Idaho's seven urban counties is 173,000 , while the average in the other 37 counties is approximately 15,500 . The stark differences highlighted above are part of the reason why Idaho was chosen as a focal SBDC. In addition, we were given access to employees of the ISBDC, which helped to make sense of the data reported.

In recent years, Idaho has experienced a unique and growing split between rural and urban communities in the midst of two phenomena: a steep rise in job creation and growth in urban areas of the state and the retirement of the baby boomer generation in mass to rural areas (Tacke, 2016). Migration patterns show that working - age residents are leaving rural counties for cities (Mansfield, 2016). At the same time, retirement - age residents are moving into rural areas of the state, effectively stagnating population growth in rural communities but at the same time depleting the eligible workforce (Tacke, 2016). Exponential growth in job creation is seen almost entirely in the state's urban counties (Tacke, 2016). While urban counties are seeing a greater influx of young and educated workers in hightech industries like robotics, the rural workforce in Idaho has become increasingly older, less educated, and is still 
Table 1. Percentage of Consulting and Impact to Rural SBDC Clients

\begin{tabular}{|c|c|c|c|c|c|c|}
\hline & 2015 & 2016 & 2017 & 2018 & 2019 & 2020 \\
\hline$\%$ of Rural Clients & $20.99 \%$ & $24.67 \%$ & $25.07 \%$ & $22.58 \%$ & $25.15 \%$ & $25.52 \%$ \\
\hline$\%$ of Consulting Hours & $20.65 \%$ & $19.56 \%$ & $17.84 \%$ & $17.07 \%$ & $24.86 \%$ & $21.47 \%$ \\
\hline \multicolumn{7}{|c|}{$\%$ of Total Rural Impact from all SBDC Clients } \\
\hline Business Starts & $25.30 \%$ & $14.29 \%$ & $17.48 \%$ & $26.73 \%$ & $21.00 \%$ & $38.46 \%$ \\
\hline Capital Raised & $13.58 \%$ & $26.83 \%$ & $30.52 \%$ & $55.00 \%$ & $42.45 \%$ & $29.40 \%$ \\
\hline Jobs Created & $20.09 \%$ & $27.03 \%$ & $43.17 \%$ & $25.30 \%$ & $26.66 \%$ & $21.32 \%$ \\
\hline Jobs Retained & $10.98 \%$ & $25.00 \%$ & $33.12 \%$ & $26.73 \%$ & $11.21 \%$ & $24.58 \%$ \\
\hline Sales Growth & $32.37 \%$ & $44.59 \%$ & $25.01 \%$ & $27.21 \%$ & $19.57 \%$ & $20.17 \%$ \\
\hline
\end{tabular}

heavily invested in traditional industries like mining, farming, and forestry (Tacke, 2016). With the depletion of their human resources by urban counties, the rural workforce has had to become more entrepreneurial, diverse, and is more likely to work in small businesses (Tacke, 2016).

Rural Idaho is remote and has very few ways to travel in terms of major freeways. For example, Electric Vehicle corridors are distinguished nationally and typically along major interstates but in Idaho, concessions had to be made for highways due to the very few ways to travel throughout the state. We now turn to examine how SBDC services differ between urban and rural areas, and detail strategies to overcome some of the challenges faced in rural settings.

\section{Strategies to Serve Rural Businesses}

In the last five years, on average, only $23.7 \%$ of Idaho SBDC clients have been located in rural areas. On average, rural consulting has only encompassed $20.0 \%$ of total consulting hours. Rural SBDC clients have accounted for $21.0 \%$ of all new business starts, $33.7 \%$ of all capital raised, $28.5 \%$ of all jobs created, $21.4 \%$ of all jobs retained, and $29.8 \%$ of all sales in the past five years. Tables $\underline{1}$ and $\underline{2}$ below depict percentage differences in services provided to rural SBDC clients as compared to urban clients. As a reference, the SBDC served 2,158 business in 2020, of which 550 were rural businesses. In this section we discuss several areas of SBDC client services we think attribute to these differences.

\section{Traditional vs. Distributed Staffing Models}

While the extent of rural environments in many states is significant, the percentage of rural clients that the SBDC serves is low in comparison. Many networks strive to serve the entire state, and have espoused the goal of serving or providing aid to at least one entrepreneur or small business in every county regardless of population. Up until 2020, this was not a standard that SBDC centers were hitting consistently. This unofficial goal was only recently achieved, due to the overwhelming amount of assistance needed by small businesses due to the Coronavirus pandemic. How SBDCs structure their staffing is different in a couple of important ways.
Table 2. Five-year Average of SBDC Clients and the Services they receive

\begin{tabular}{|c|c|}
\hline & 5-Year Average \\
\hline \% of Rural Clients & $23.7 \%$ \\
\hline \% of Consulting Hours & $20.0 \%$ \\
\hline \% of Total Rural Impact from all SBDC Clients \\
\hline Business Starts & $21.0 \%$ \\
\hline Capital Raised & $33.7 \%$ \\
\hline Jobs Created & $28.5 \%$ \\
\hline Jobs Retained & $21.4 \%$ \\
\hline Sales Growth & $29.8 \%$ \\
\hline
\end{tabular}

\section{Traditional Staffing Models}

A traditional staffing model consists of a centralized office where consultants and other administrative staff work. In this model, consultants rarely, if ever, leave the office to meet with clients. Instead, clients come into these offices to receive the services they provide. If clients are unable to travel to the office of the consultant, consultants may use video communication software like Zoom or Skype for Business provided by the network to meet with clients. However, under normal circumstances, this is very rare. That said, due to the unusual circumstances surrounding the Coronavirus pandemic, since March of 2020, all offices of the SBDC are actively using Zoom as a means to meet with clients, regardless of the normal method of interacting with their clients. Typically, traditional staffing models work best in regions with high population density and more consistent means of infrastructure in terms of travel. In short, the regions that use this staffing model are usually located in urban environments working with entrepreneurs and small business owners that are likely to be more educated and have easier access to technology and resources. The services and training that they provide can be the same or similar to a distributed staffing model but can also vary based on education and industry. 


\section{Distributed Staffing Models}

A common SBDC practice in states with large rural populations is to have several regional offices that have a distributed staffing model, whereby business consultants are either remotely located in rural areas or travel to rural areas to consult. Often, these regions have offices that are located within overwhelmingly rural communities or located in more urban centers - that nationally speaking would be considered rural. These regions using the distributed staffing model also have small budgets and work on a reduced amount of staffing.

This approach has allowed the SBDC consultants to be more responsive to the needs of local companies, build stronger community relationships, and deliver quality consulting. Almost all of these rural consultants have deeprooted ties to their communities; they've grown up there, raised a family there, owned a prominent business there or are involved with their county's myriad of different network partners. In regions that use a distributed staffing model, it is mandatory that consultants not only have the technical know-how and industry knowledge but that they truly care about the communities where they work. In interviews with both directors in Idaho, they stressed that community is one of the most important factors when working with rural regions. Often times, consultants in these regions become an incredibly integral part of their client's small business but it may take longer for consultants to gain their clients trust than in a traditional staffing model in an urban area.

In addition to recruiting consultants with community ties, they also rely on the communities themselves for marketing purposes. In these regions, word of mouth and personal referrals are the largest forms of marketing. In 2019, $26.5 \%$ of electronic requests for counseling came from these sources (word of mouth referrals are those that come from business-to-business sources). In 2020, the number of referrals from these sources increased slightly to $27.0 \%$. Region Directors leverage their region's network partners and community leaders who champion the SBDC. These individuals and companies are crucial to the inflow of new clients and ultimately pivotal to the survival of small towns. On occasion, network partners become consultants for our regional offices. As of September 2019, there were three rural consultants who are also community leaders and Economic Development Corporation Directors in their respective areas.

The common factor shared by both Idaho's rural and urban communities is that small business employment consists of half of all employed people (Cicero, 2018). In Idaho, there is approximately one small business for every 11 people and over $99 \%$ of businesses are small businesses (Cicero, 2018). In addition to being the largest source of the state's employment, about two-thirds of rural Idaho small business owners are dependent on the incomes of their small businesses for the majority of their living expenses (Cicero, 2018).

\section{Level of Service Medium}

While SBDC centers strive to provide the same beneficial services to all clients, both urban and rural, there are some differences in the medium used for most of the client meetings between these two populations. Among the most significant differences is the disparity in the percentages of meetings that are completed face-to-face. In 2019, our SBDC sample conducted $10.3 \%$ of client meetings with entrepreneurs in urban areas in a face-to-face format, while only $5.25 \%$ of meetings with rural clients were in person. Additionally, $21.7 \%$ of meetings with urban clients were conducted via video meetings, while $14.2 \%$ of meetings with rural clients used video communications. Conversely, $35.3 \%$ of communications with urban clients used phone or email, while the number was much higher (43.5\%) for rural clients. Taken together, this shows that the richness of consulting time spent with urban entrepreneurs is significantly greater than that spent with rural ones. These statistics in tandem with the lack of technology access and lower level of education in rural areas demonstrate the need for SBDCs to conduct more intensive outreach and marketing that are different in terms of medium and message than that used to target new urban entrepreneurs.

\section{Expertise in Training}

Some of the areas of services that SBDCs offer involves training on how to use various business-related technologies. Those technologies vary by the business, but often include applications such as QuickBooks and Square. SBDC clients are offered low-cost trainings to learn how to use these programs, which should make managing certain aspects of the business more efficient. However, without knowledge about how to use these various technologies or related technologies, they are of little use, and instead may end up eating up valuable resources as business owners struggle to learn them. Moreover, general observations from SBDCs are that entrepreneurs in urban areas are much more likely to have experience with and knowledge about those types of technologies, while entrepreneurs in rural areas are less likely to have experience and know how. This is further perpetuated by rural flight by younger generations and the increase in retirement age populations migrating from the surrounding states, effectively stagnating the population and decreasing the eligible workforce in one fell swoop. Rural businesses that previously would have been passed down are more often than not closing because there is no new generation to run them and their owners have no means to learn the infinite number of intricacies of new technology.

In a similar vein, guidance on the use of social media platforms has parallel challenges. Many small businesses use social media to help with various marketing efforts (Fachrunnisa et al., 2020). In fact, it has been found to be a relatively inexpensive and efficient way to market. However, as with the technologies mentioned above, there is a disparity in fluency on these platforms between urban and rural entrepreneurs.

While these technologies can both be quite useful for new business owners, SBDC consulting on them is limited. Additionally, the training that is offered is generally geared towards and helps with those who have some experience with the technologies or something similar, working to only compound the varying benefits to these two populations. 
Table 3. Differences in Services Between Rural and Urban SBDC Clients

\begin{tabular}{|c|c|c|}
\hline $\begin{array}{l}\text { Point of } \\
\text { Difference }\end{array}$ & Rural & Urban \\
\hline Staffing Models & Distributed Model & Traditional Model \\
\hline $\begin{array}{l}\text { Level of Service } \\
\quad \text { Medium }\end{array}$ & $\begin{array}{c}5.25 \% \text { of meetings face-to-face } \\
14.2 \% \text { via video } \\
43.5 \% \text { via phone or email }\end{array}$ & $\begin{array}{c}10.3 \% \text { of meetings face-to-face } \\
21.7 \% \text { via video } \\
35.3 \% \text { via phone or email }\end{array}$ \\
\hline $\begin{array}{l}\text { Technology } \\
\text { Expertise / } \\
\text { Training }\end{array}$ & $\begin{array}{l}\text { Less experience with technologies, so need more } \\
\text { training with technologies provided. }\end{array}$ & $\begin{array}{l}\text { More experience with technologies, so benefit } \\
\text { more from the technologies }\end{array}$ \\
\hline Access to Capital & $\begin{array}{l}\text { Receive } 33 \% \text { of capital raised } \\
\quad \text { Average Loan }=\$ 103 \mathrm{~K}\end{array}$ & $\begin{array}{l}\text { Receive } 67 \% \text { of capital } \\
\text { Average Loan }=\$ 76 \mathrm{~K}\end{array}$ \\
\hline Time & Average consultation meeting lasts .56 hours & Average consultation meeting lasts .61 hours \\
\hline PPP Loans & $\begin{array}{l}\text { Longer period to receive and more complex process to } \\
\qquad \text { apply }\end{array}$ & $\begin{array}{l}\text { Shorter period to receive and more } \\
\text { streamlined process }\end{array}$ \\
\hline
\end{tabular}

\section{Access to Capital}

One of the primary services offered by SBDCs is access to their network of lenders. Moreover, one of the most important factors in determining the success of getting past ideation, is the cost and acquisition of startup capital (Dunne \& McBrayer, 2019). In terms of differences in access to capital, data present a mixed outlook. As can be found in Table 1, over a period from 2015 through 2020 rural entrepreneurs only received a yearly average of $33 \%$ of the total capital received by SBDC clients. That being said, the average loan amount in 2020 was $\$ 103,888$ for rural businesses while it was $\$ 76,525$ for urban clients. While this is promising for rural entrepreneurs, we are examining further what other factors might be contributing to that higher average for rural clients. For example, we will look for outliers, such as one or two rural clients that might be skewing that average. That said, the current information paints a positive picture of access to capital for rural entrepreneurs.

\section{Time}

While it has already been explained that rural entrepreneurs receive less face-to-face as well as video communications with SBDC consultants, it is also worth noting that the amount of time spent with rural clients is lower. On average SBDC consultants spend .56 hours per meeting with rural clients, while meetings with urban clients last .61 hours on average. Taken together with earlier observations about differences in the services received, we see additional shortfalls of service to rural clients.

\section{PPP Loans}

In addition to the above differences, which occur similarly on an ongoing basis, we also briefly analyzed an element of SBDC service that was specific to the landscape surrounding the Coronavirus pandemic. Specifically, there were some differences in access to Paycheck Protection Programs (PPP) loans offered by the SBA. Interviews with SBDC personnel in the Idaho SBDC found that their rural clients waited longer to receive PPP loans and that the process was more complex and difficult for them. One possible explanation of this observation is that many rural clients tend to be in the traditional industries, typically mining or agriculture. At the beginning of the pandemic, any business that fell under the wide umbrella of Agriculture was directed to get their relief from the United States Department of Agriculture (USDA) and was unable to apply for a PPP or Economic Injury Disaster Loan (EIDL), which contributed to the complexity and length of time to receive assistance and relief. USDA's relief was also less publicized and took longer to start accepting applications because it's infrastructure was smaller than that of its SBA counterpart. It is worth noting that this has since changed. The loan forgiveness process has also been extremely difficult to navigate for both rural and urban entrepreneurs. While it is unknown, the process for loan forgiveness is likely to be more difficult for rural clients due to the observed differences mentioned earlier.

\section{Proposed Solutions}

While the different outcomes rural versus urban SBDC clients receive cannot be entirely managed, we propose practical changes SBDCs can adopt the improve this difference and better achieve the goals of providing better services to rural entrepreneurs.

Better use of metrics for rural populations. While there are stated goals, at national and local levels, to accelerate business success for rural entrepreneurs, there is currently little done in the way of instituted metrics for use with rural clients. SBDCs may be held to different standards or goals by other stakeholders like host institutions (colleges and universities), State Board of Education, etc. but the goals are merely checkpoints with no consequences if not met. Currently, SBA holds SBDCs to several standard Key Performance Indicators (KPIs) of economic impact as an overall program: jobs supported, jobs retained, jobs created, business starts, capital raised, and sales increase. But there are no metrics collected related to rural entrepreneurs even though there is a SBA stated focus area of rural entrepreneurship and development. The data we collected from SBDCs shows a lack of success measures being collected for 
these businesses Thus, we believe it would help rural entrepreneurs for SBDC consultants to institute KPI metrics that they can use with rural clients. For example, it would be helpful to see year-over-year growth in services provided, for both urban and rural clients, as well as better metrics of impact, such as company revenues, growth, etc.

Face-to-face consulting. As this research highlights, the level of service and richness of consultative communications provided to rural SBDC clients is lacking compared to their urban counterparts. Due in part because of the obvious physical distance challenges, rural entrepreneurs receive much less face-to-face consultative services than urban entrepreneurs. We believe one way to help in this regard is to institute more distributed staffing models in SBDCs in states or regions where large rural populations exist. This staffing model, partially used in the population studied here, has resulted in more opportunities for in-person consulting for rural clients and a greater amount of impact recorded in rural communities. Therefore, we propose that this staffing model is expanded in those regions and instituted in SBDCs that do not currently use them.

Targeted Marketing Efforts. In addition to expanding faceto-face consulting in rural areas, it is also important the SBDCs utilize appropriate methods to target and market to rural business owners. Much of SBDC marketing efforts rely on social media. Thus, if rural businesses are less actively engaged on technology platforms, they may not have the initial contact with the centers. Accordingly, we recommend SBDCs that serve more rural areas, utilize marketing efforts that are more specific to the areas they serve. For example, these centers could utilize trade shows or attend community events, where rural business owners may be present.

Better access and training with technology. This recommendation is a two-part suggestion. We propose that SBDCs offer more access to different technologies for rural entrepreneurs. Providing improved technologies to entrepreneurs in rural areas could improve their ability to receive help from SBDC consultants in the form of more rich video communications. In combination with more distributed staffing models, this could help improve the amount of face-to-face and/or more rich communications methods, which in turn could improve the amount of overall time spent helping rural clients.

The second part of this recommendation is to improve training for rural SBDC clients on how to use the various technologies to which they are given access. By providing more training (both hands-on and virtual) on the efficient uses of such technologies, clients in rural settings could benefit more from them and SBDC consultants could spend more time providing other valuable consulting services.

Accelerator opportunities for rural entrepreneurs. Many SBDCs located in urban centers also run, or have access to business incubators and accelerators, to help entrepreneurs get their businesses started successfully. While moving these types of accelerators into rural areas may not be possible, we propose that SBDCs encourage their rural clients to utilize these opportunities. In fact, because of the success of these offerings, we would like to see SBDCs initiate some type of program aimed at getting rural entrepreneurs involved with accelerators.

\section{Conclusion}

As the workforces in rural areas across the country become even more depleted, and small businesses struggle to have access to other important resources, it is extremely important that entities such as the SBA, USDA, and SBDCs continue to reach out and assist rural entrepreneurs. And, even though limited resources are a reality, the significance of these rural businesses to local communities, makes it imperative to assist in revitalizing these economies, particularly in states with significant proportions of rural communities. The current research highlights several areas where rural entrepreneurs are at a significant disadvantage when compared to their urban counterparts. However, we believe that by addressing these shortcomings, this important population of business owners can be successfully serviced. By using effective marketing strategies, and leveraging community leaders, the SBDC has and will continue to help slow and reverse rural flight and simultaneously help to educate the rural community. By utilizing more distributed staffing models and increasing the number of rural consultants, the SBDC can expand its reach to all areas they serve and increase the number of face-to-face consultation meetings they provide. Additionally, by furthering their marketing efforts, and instituting better metrics for assessing impact on rural entrepreneurs, they will be better suited to addressing the unique needs of that population. Providing better access to helpful technologies, as well as implementing a strategy to provide more technology training to rural clients will also help SBDCs be more accessible to our rural populations. We see this as an important step in serving the rural populations in a more effective way, and in the way that is espoused by the SBA and SBDCs across the country. 


\section{REFERENCES}

America’s Small Business Development Center. (2021). SBDC Services. https://americassbdc.org/

Chrisman, J. J. (2019). SBA; and the "Economic Impact of Small Business Development Center Counseling Activities in the United States: 2017-2018.”

Cicero. (2018). Idaho Small Business Development Center Rural Small Business Analysis and Awareness Study.

Dunne, T. C., \& McBrayer, G. A. (2019). In the interest of small business' cost of debt: A matter of CSR disclosure. Journal of Small Business Strategy, 29(2), 58-71.

Fachrunnisa, O., Adhiatma, A., Ab Majid, M. N., \& Lukman, N. (2020). Towards SMEs' digital transformation: The role of agile leadership and strategic flexibility. Journal of Small Business Strategy, 30(3), 65-85.

Howorth, C., Tempest, S., \& Coupland, C. (2005). Rethinking entrepreneurship methodology and definitions of the entrepreneur. Journal of Small Business and Enterprise Development, 12(1), 24-40. htt ps://doi.org/10.1108/14626000510579626

Mansfield, E. (2016, December 23). Rural Idaho: Population Decline to Reduce Available Labor Source in Next Decade. Idaho Department of Labor. https://id ahoatwork.com/2016/12/23/rural-idaho-population-d ecline-to-reduce-available-labor-source-in-next-deca de/
Morrow, H. (2017, January 18). Defining Rural Idaho Presents Challenges. Idaho Department of Labor. http s://idahoatwork.com/2017/01/18/defining-rural-idah o-presents-challenges/

Peake, W. O., Yates, M., Barber, D., \& McMillan, A. (2020). Do entrepreneurs do good deeds to maximize wins or avoid losses? A regulatory focus perspective. Journal of Small Business Strategy, 30(3), 33-46.

Small Business Trends. (2021). Small Business Statistics. https://smallbiztrends.com/small-business-statistics

Tacke, K. (2016, December 22). Rural Idaho Today: An Overview of Components Impacting its Economy. Idaho Department of Labor. https://idahoatwork.com/ 2016/12/22/rural-idaho-today-an-overview-of-compo nents-impacting-its-economy/

U.S. Small Business Administration Office of Small Business Development Centers. (2019). Small Business Administration. OSBDC Funding Opportunity FY/CY 2019. https://www.sba.gov/sites/default/files/r esources_articles/2019_SBDC_Funding_Opportunity_F inal.pdf 